\title{
SIMCA Pattern Recognition in the Analysis of Streptomycete Fatty Acids
}

\author{
By G. S. SADDLER, ${ }^{\prime}$ A. G. O’DONNELL, ${ }^{2 *} M$. GOODFELLOW' AND \\ D. E. MINNIKIN ${ }^{3}$ \\ Departments of ${ }^{1}$ Microbiology, ' - Soil Science and ${ }^{3}$ Organic Chemistry, The University, \\ Newcastle upon Tyne NEI 7RU, UK
}

(Received 13 November 1986; revised 28 December 1986)

Biomass from representative strains of Streptomyces cyaneus and related taxa was degraded using an alkaline methanolysis procedure. The resultant fatty acid methyl esters were analysed by gas chromatography and the quantitative data examined using the SIMCA statistical package. The $S$. cyaneus strains were recovered in two major clusters. The larger of these contained sixteen strains which had been previously classified as $S$. cyaneus in a numerical phenetic survey. The remaining $S$. cyaneus strains formed a heterogeneous aggregate cluster together with representatives of other streptomycete species. A third cluster encompassed a number of blue-spored streptomycetes from soil. Disjoint principal components analysis in conjunction with cross-validation analyses demonstrated that the $S$. cyaneus group and the bluespored soil isolates could be represented by statistically stable principal component models. The fact that the initial, numerically circumscribed, $S$. cyaneus taxon was only partially recovered by the numerical analysis of fatty acid data supports the view that this taxon contains strains which are not entirely typical of the cluster, despite their high degree of similarity with other members. These preliminary findings suggest that models based on fatty acid data could be used for identifying unknown streptomycetes to established taxa and for the definition of novel streptomycetes.

\section{INTRODUCTION}

Industrial screening programmes designed to find and evaluate new microbial metabolites or biocatalytic processes rely on the selective isolation and characterization of novel organisms (Goodfellow \& Williams, 1986). It is important that the circumscription of novel taxa is based on sound taxonomic principles and that data on new and established taxa are objectively analysed.

The importance of chemical data in actinomycete systematics is well established (Minnikin \& O'Donnell, 1984). In particular numerical phenetic classifications can be evaluated in light of whole-organism fatty acid data (O'Donnell et al., 1984; Embley et al., 1984). Often, such comparisons have been somewhat subjective with fatty acid profile similarities determined qualitatively. Using standardized growth and analytical conditions, however, reproducible fatty acid profiles, suitable for multivariate statistical analysis can be obtained (Saddler et al., 1986). This approach not only provides an objective alternative to visual comparisons of fatty acid profiles, but can also give valuable taxonomic information for identification and classification below the genus level (O’Donnell, 1985).

Streptomycetes which form a blue aerial spore mass have frequently been grouped together (Hütter, 1962; Pridham \& Tresner, 1974; Korn et al., 1978), and in an extensive numerical phenetic survey of the genus Streptomyces (Williams et al., 1983) thirteen of the nineteen representative blue-spored taxa were recovered in a major phenon, the $S$. cyaneus cluster. This

Abbreviations: SIMCA, soft independent modelling of class analogy; PCA, principal components analysis; KNN, $\mathrm{K}$ nearest neighbours analysis; FAME, fatty acid methyl ester. 
taxon also contained strains producing grey or red spores and was heterogeneous with respect to spore chain ornamentation as some strains formed smooth spores, but the remainder formed spiny spores. The major streptomycete clusters recovered by Williams et al. (1983) varied in size ( 6 to 71 strains) and in their homogeneity. It was therefore suggested that they be regarded as species-groups until further information was available.

In the present study the fatty acid profiles of representative $S$. cyaneus strains, additional bluespored streptomycetes from soil and selected streptomycete reference strains from other numerically defined taxa (see Table 1) were examined together with recently isolated actinomycetes which contained LL-diaminopimelic acid and glycine in the wall peptidoglycan but lacked characteristic sugars (wall chemotype I, Lechevalier \& Lechevalier, 1970). The fatty acid data were examined to determine whether the numerical analysis of fatty acid profiles using the SIMCA statistical package (Soft Independent Modelling of Class Analogy; Wold, 1976; Wold \& Sjøstrom, 1977) could clarify the taxonomy of $S$. cyaneus strains and help to identify unknown streptomycetes.

\section{METHODS}

Organisms. The test strains (Table 1) were maintained as frozen glycerol suspensions at $-25^{\circ} \mathrm{C}$ (Wellington \& Williams, 1978). Binomials in inverted commas are not on the Approved List of Bacterial Names (Skerman et al., 1980 ) and have not been published since the 1st of January 1980. ND, Not determined.

Table 1. Cluster allocation, morphological properties and pigmentation properties of the test strains

Cluster and ISP strain histories are after Williams et al. (1983). The acidophilic, blue-spored and facultatively autotrophic isolates were supplied by K. E. Simpson, T. Whitham and C. Falconer, respectively (Department of Microbiology, The University of Newcastle upon Tyne, UK). Data on the remaining strains is from Williams et al. (1983).

\begin{tabular}{|c|c|c|c|c|c|c|}
\hline Cluster & $\begin{array}{c}\text { Strain } \\
\text { no. }\end{array}$ & Received as: & $\begin{array}{c}\text { SIMCA } \\
\text { no. }\end{array}$ & $\begin{array}{l}\text { Mass } \\
\text { colour }\end{array}$ & $\begin{array}{l}\text { Chain } \\
\text { morphology }\end{array}$ & Ornamentation \\
\hline Cluster 18 & 5106 & S. azureus & 47 & Blue & Spirales & Smooth \\
\hline \multirow[t]{26}{*}{ (S. cyaneus) } & 5140 & 'S. bicolor' & 43 & Blue & Spirales & Spiny \\
\hline & 5085 & S. chartreusis & 41 & Blue & Spirales & Spiny \\
\hline & 5144 & S. coeruleofuscus & 26 & Blue & Spirales & Spiny \\
\hline & 5145 & S. coeruleorubidus & 25 & Blue & Spirales & Spiny \\
\hline & 5146 & S. coerulescens & 23 & Blue & Spirales & Spiny \\
\hline & 5107 & S. curacoi & 35 & Blue & Spirales & Spiny \\
\hline & 5108 & S. cyaneus & 20 & Blue & Spirales & Spiny \\
\hline & 5592 & 'S. peruviensis' & 8 & Blue & Spirales & Spiny \\
\hline & 5084 & $S$. caelestis & 37 & Blue & $\begin{array}{l}\text { Retinaculi- } \\
\text { aperti }\end{array}$ & Smooth \\
\hline & 5185 & S. bellus & 32 & Blue & $\begin{array}{l}\text { Retinaculi- } \\
\text { aperti }\end{array}$ & Spiny \\
\hline & 5483 & S. luteogriseus & 15 & Grey & Spirales & Smooth \\
\hline & 5133 & S. resistomycificus & 31 & Grey & Spirales & Smooth \\
\hline & 5293 & S. arenae & 45 & Grey & Spirales & Spiny \\
\hline & 5013 & S. echinatus & 40 & Grey & Spirales & Spiny \\
\hline & 5482 & S. iakyrus & 27 & Grey & Spirales & Spiny \\
\hline & 5588 & S. neyagawaensis & 34 & Grey & Spirales & Spiny \\
\hline & 5129 & S. collinus & 24,39 & Grey & $\begin{array}{l}\text { Retinaculi- } \\
\text { aperti }\end{array}$ & Smooth \\
\hline & MAV & S. paradoxus & 16 & Grey & $\begin{array}{l}\text { Retinaculi- } \\
\text { aperti }\end{array}$ & Smooth \\
\hline & 5212 & S. pseudovenezuelae & 28 & Grey & $\begin{array}{l}\text { Rectiflexi- } \\
\text { bilis }\end{array}$ & Smooth \\
\hline & 5467 & S. cinnabarinus & 19 & Red & Spirales & Smooth \\
\hline & 5154 & S. fumanus & 29 & Red & Spirales & Smooth \\
\hline & 5531 & 'S. pallidus' & 17 & Red & Spirales & Smooth \\
\hline & 5207 & 'S. violochromogenes' & 44 & Red & Spirales & Smooth \\
\hline & 5206 & S. janthinus & 42 & Red & Spirales & Spiny \\
\hline & 5166 & S. longisporus & 22 & Red & Spirales & Spiny \\
\hline & 5277 & $S$ roseoviolaceus & 18 & Red & Spirales & Spiny \\
\hline
\end{tabular}


Table 1 (continued)

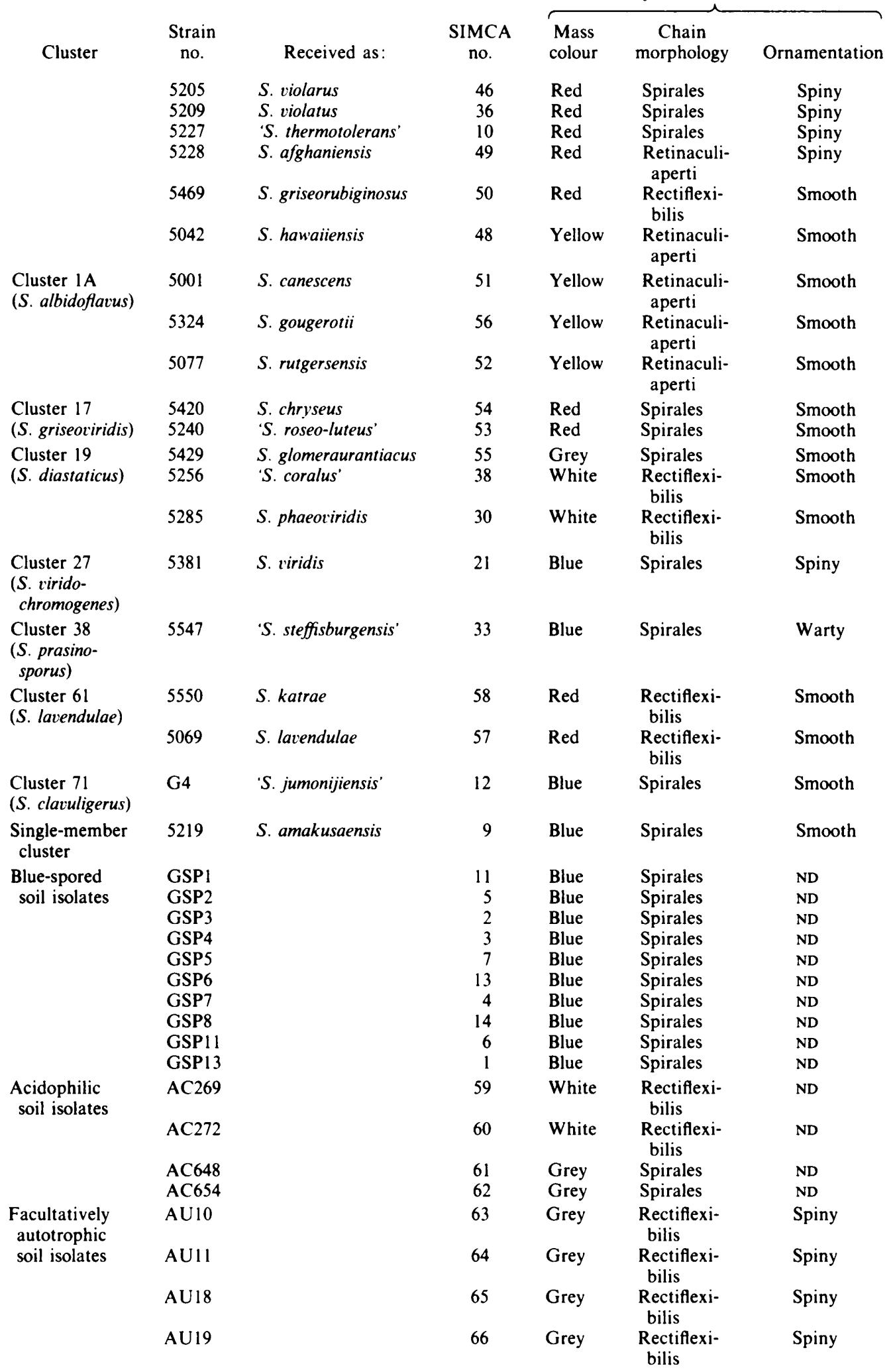


Preparation of biomass. A thawed glycerol suspension of each strain was used to inoculate $100 \mathrm{ml}$ of modified Sauton's medium (Mordarska et al., 1972) in a $250 \mathrm{ml}$ flask. The acidophilic actinomycetes were cultivated at $\mathrm{pH}$ 4.5 and the remaining strains at $\mathrm{pH} 7 \cdot 2$. The inoculated flasks were shaken ( 200 r.p.m.) for $3 \mathrm{~d}$ at $25^{\circ} \mathrm{C}$. Samples $(10 \mathrm{ml})$ of the starter cultures were used to inoculate $300 \mathrm{ml}$ of the same medium in 11 flasks which were incubated as before, but for 7 to $10 \mathrm{~d}$ as recommended by Saddler et al. (1986). Cultures were checked for purity, killed by addition of $3 \mathrm{ml}$ formalin $(1 \%, \mathrm{v} / \mathrm{v})$, harvested by centrifugation at $3000 \mathrm{~g}$ for $20 \mathrm{~min}$, washed three times with distilled water, recentrifuged and freeze-dried.

Extraction and analysis of fatty acids. Dried biomass $(50 \mathrm{mg})$ was degraded at $75{ }^{\circ} \mathrm{C}$ for $3 \mathrm{~h}$ with $5 \%(\mathrm{w} / \mathrm{v})$ aqueous tetrabutylammonium hydroxide $(2 \mathrm{ml})$ followed by reaction with $2.5 \%(\mathrm{v} / \mathrm{v})$ iodomethane in dichloromethane $(1 \mathrm{ml})$ at room temperature for $1 \mathrm{~h}$. Evaporation of the lower dichloromethane layer gave crude methyl esters (D. E. Minnikin, A. G. O'Donnell, J. H. Pariett and M. Goodfellow, unpublished data). Analytical and preparative thin-layer chromatography (TLC) of methyl esters were done as described by O'Donnell $e t$ al. (1982).

Gas chromatography (GC) of light petroleum (b.p. $60-80^{\circ} \mathrm{C}$ ) solutions of purified fatty acid methyl esters (FAMEs) was done using a Shimadzu GC Mini-2 chromatograph equipped for simultaneous analysis on both $50 \mathrm{~m}$ bonded OV-1 and $25 \mathrm{~m}$ non-bonded Silar 10C (Alltech) fused silica capillary columns. Retention times and the relative proportions of each FAME, expressed as a proportion of the total area, were measured using a Shimadzu CE1B computing integrator. The identity of individual esters was established by comparison with the retention times of standard FAMEs mixtures and by their chromatographic behaviour both on the polar and apolar columns. Straight chain standards $\left(\mathrm{C}_{12}-\mathrm{C}_{18}\right)$ were obtained from Sigma. Branched chain standards $\left(C_{14}-C_{18}\right)$ were extracted from Bacillus subtilis NCIB 3610 . The percentage fatty acid composition, expressed relative to the total peak area, for each test strain is presented in Table 2.

Statistical methods. Principal components analysis (PCA; Gower, 1966) and K nearest neighbours analysis (KNN; Fix \& Hodges, 1951) of the quantitative fatty acid data were done using the SIMCA package. SIMCA is a commercially available program (Sepanova AB, Enskede, Sweden) which can run on a variety of microcomputers and mainframes. Nearest neighbours analysis, by providing information on the relationships between individual strains, made it possible to assess the relevance of the clusters recovered using principal components analysis (see Discussion for further details). When used for identification, SIMCA describes each taxon or group of strains as a separate principal components model or class. This procedure of disjoint principal components analysis (Wold, 1976; Wold \& Sjøstrom, 1977) means that the final data matrix can include information on a variety of taxa in which the within group variation is modelled independently and therefore not assumed to be equal.

Separate principal components models (classes) were constructed for both blue-spored soil isolates and $S$. cyaneus strains. The classes were not separately scaled (Blomquist et al., 1979b,c). The number of statistically significant components necessary to describe each class model was determined by cross-validation (Wold, 1978). This latter procedure provided a useful estimate of how much of the variance within a class data matrix accurately described the class (systematic variation) and how much was random noise (Blomquist et al., 1979b,c). In this way, the statistical stability and therefore the predictive value of each class model was determined (Blomquist et al., $1979 b, c)$. Geometrically, a principal component or class model can be seen to represent a region in multidimensional space in which the standard deviation can be used to define the confidence regions of the group. In the present study, linear multiple regression was used to fit every fatty acid profile in the data matrix (Table 1 ) to each class model (Blomquist $e t a l ., 1979 b, c)$. Strains were considered to be members of a class when they fell within the class confidence interval. Detailed mathematical descriptions of the SIMCA method are available (Wold \& Sjøstrom, 1977; Blomquist et al., 1979a).

\section{RESULTS}

Whole-organism methanolysates of the test strains showed the presence of predominant spots $\left(R_{F} 0.8\right)$ corresponding to non-hydroxylated FAMEs (Minnikin et al., 1980); hydroxylated fatty acids $\left(R_{F} 0.2\right)$ were not detected. Results of the GC analysis of the non-hydroxylated long-chain components are shown in Table 2 . All of the strains produced qualitatively similar profiles with 12-methyltetradecanoic (anteiso-15) and 14-methylpentadecanoic acid (iso-16) as the major components. However, marked quantitative variations with respect both to the major components and to 12-methyltridecanoic (iso-14), 13-methyltetradecanoic (iso-15) and hexadecanoic acids $(16: 0)$ were observed between strains.

The results obtained by applying PCA to the data in Table 2 are shown in Fig. 1. Results of KNN are imposed on top of the scatter diagram, with each strain linked to its nearest neighbour. This latter analysis highlights relationships which are not evident by PCA alone. Thus, the relationship of $S$. cinnabarinus ISP 5467 (strain 19) with the facultatively autotrophic 


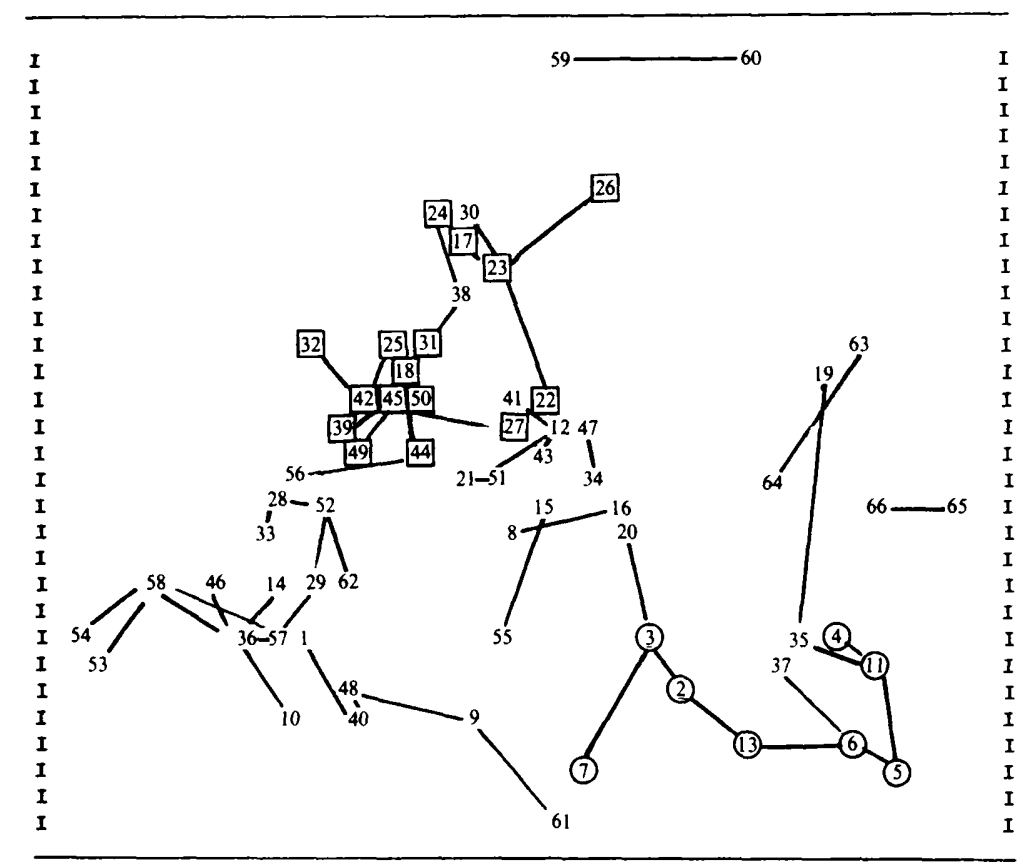

Fig. 1. PCA of FAMEs of the test strains (Table 2). The strains have been linked together using KNN. Strains used to define the models $(\square, S$. cyaneus strains; $O$, blue-spored soil isolates) have been identified.

actinomycetes was more apparent than real as this organism is more closely related to $S$. curacoi ISP 5107 (strain 35).

With the exception of acidophilic cultures AC648 (strain 61) and AC654 (strain 62) and two blue-spored soil isolates GSP13 (strain 1) and GSP8 (strain 14) which appeared to cluster with some of the $S$. cyaneus type strains, the recent soil isolates (Table 1) were recovered as distinct groups. On the basis of the KNN analysis, S. curacoi ISP 5107 (strain 35), S. caelestis ISP 5084 (strain 37), S. cyaneus strains, S. cinnabarinus ISP 5467 (strain 19) and S. cyaneus ISP 5108 (strain 20) were also associated with the blue-spored soil isolate group.

Three major groups were revealed by KNN. The 19 strains assigned to the largest group included 16 organisms classified in the $S$. cyaneus cluster (Williams et al., 1983). These 16 strains, which were heterogeneous with respect to classical morphological criteria such as spore arrangement and colour of aerial spore mass, were then used to form a SIMCA class model using disjoint principal components analysis (Wold, 1976; Wold \& Sjøstrom, 1977). The second group accommodated 18 strains comprising seven representatives of the $S$. cyaneus cluster, seven streptomycete reference strains, two acidophilic isolates and two blue-spored soil isolates. This apparently heterogeneous group was not studied further.

The final group contained eight of the ten blue-spored soil isolates and four $S$. cyaneus strains $(35,37,19$ and 20$)$. The former were subject to further study using disjoint PCA, whilst the latter were treated as unknowns. Both the $S$. cyaneus and blue-spored soil isolate classes were represented by statistically stable principal components models, significant to three principal components, as determined by cross-validation (Wold, 1978). The 17 strains excluded from the three major groups were recovered as minor groups which, because of their limited size, were unsuitable for further statistical analysis.

The result of plotting the distance (unweighted object standard deviation), calculated using linear multiple regression, of each of the test strains from the class model derived from the bluespored environmental isolates ( $\mathrm{x}$-axis) against that for the class model of the $S$. cyaneus strains (y-axis) is shown in Fig. 2. Imposing $95 \%$ confidence intervals for each class divides the plot into 


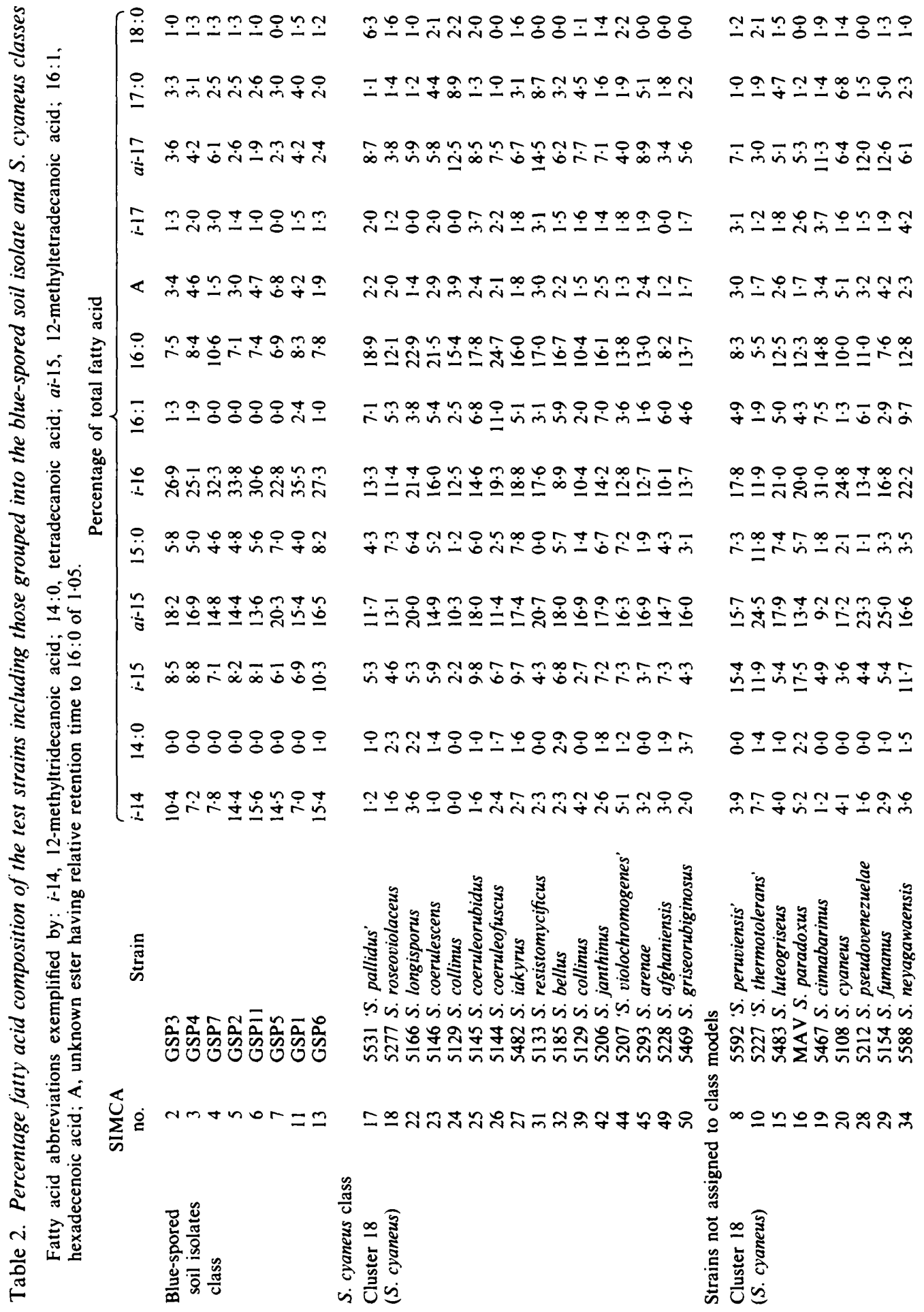




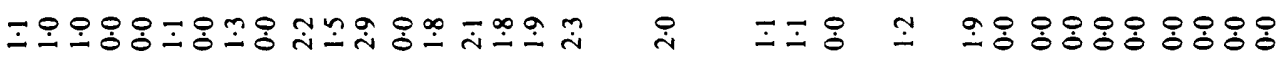

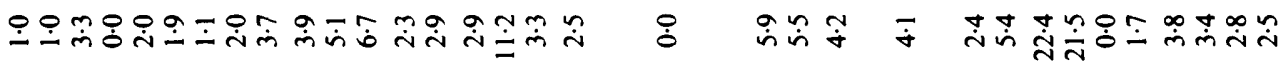

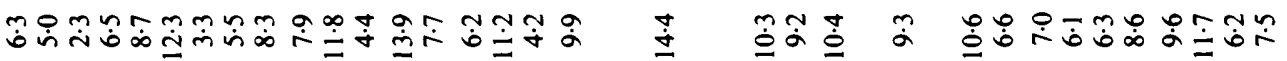

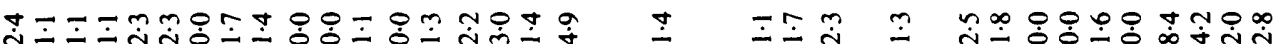

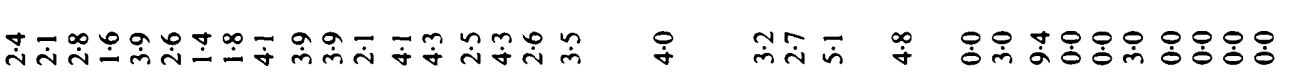

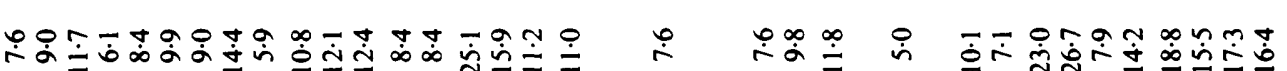

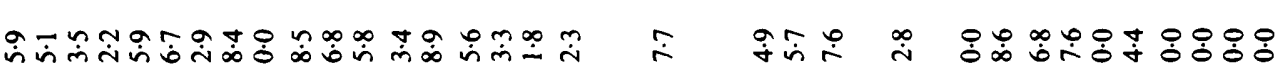

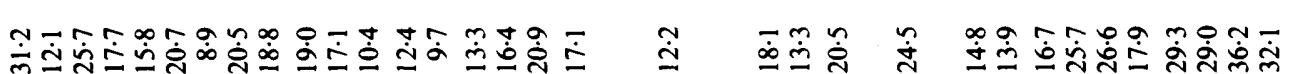

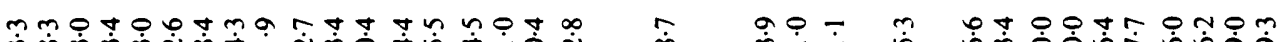

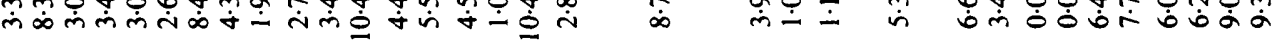

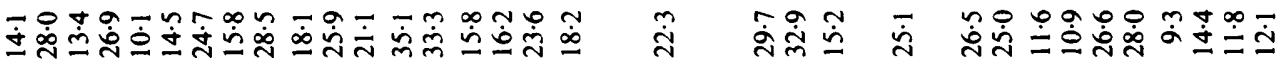

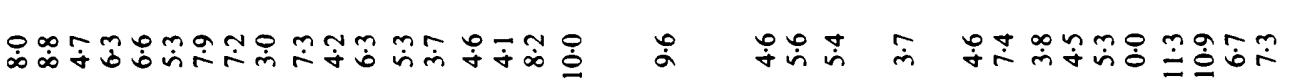

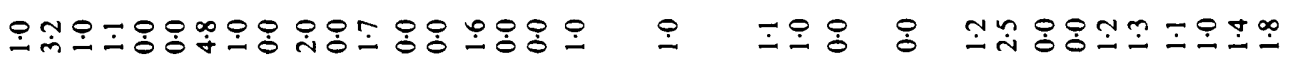

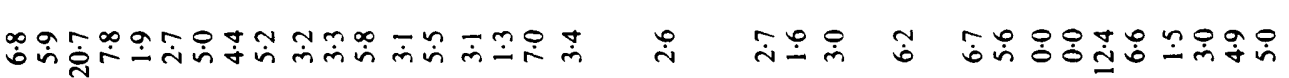




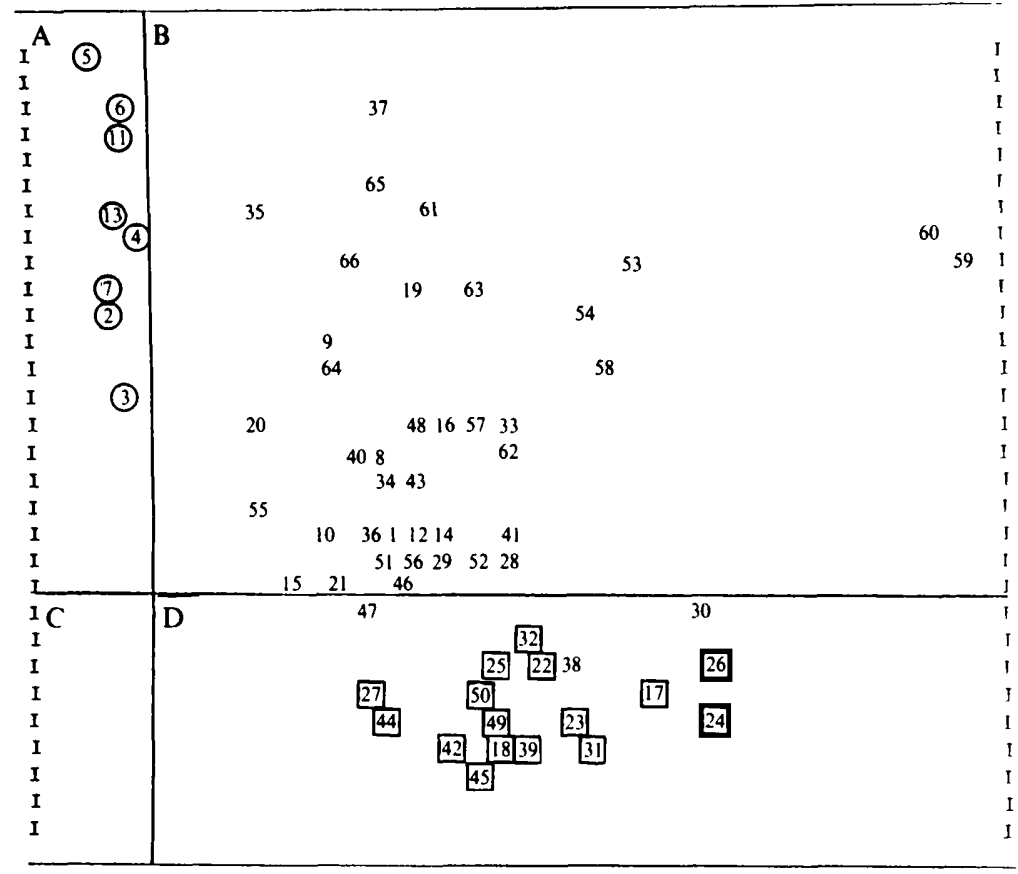

Fig. 2. Residual SD plot of the blue-spored environmental class (x-axis) against the $S$. cyaneus class (y-axis). Region A contains strains uniquely identified to the environmental isolates group (class); region D contains strains recovered in the $S$. cyaneus group; region $\mathrm{C}$ contains intermediates between the two taxa and region B consists of strains not identified to any group. All the strains assigned to the soil isolates class were identified to the group, as were all of the strains assigned to the $S$. cyaneus class; however, in addition strains 30,38 and 47 were also identified to this group. Strains used to define the models ( $\square, S$. cyaneus strains; $\bigcirc$, blue-spored soil isolates) have been identified.

four distinct regions. Strains recovered in region A can be identified as belonging to the bluespored environmental isolate class and those in region $\mathrm{D}$ can be assigned to the $S$. cyaneus class. Organisms allocated to region $C$ in such plots represent intermediate strains which cannot be unambiguously assigned to either group. Region $\mathrm{B}$, an area outside the class confidence intervals of both taxa, contains strains which are distinct from the two class models.

It is evident that the blue-spored soil isolates form a distinct group with no overlapping strains (region A; Fig. 2). Similarly all 16 members of the $S$. cyaneus class were recovered in region D, together with $S$. azureus ISP 5106 (strain 47; cluster 18), 'S. coralus' ISP 5265 (strain 30; cluster 19) and $S$. phaeoviridis ISP 5285 (strain 38; cluster 19). Since none of the test strains were recovered in region $\mathrm{C}$, the $S$. cyaneus and soil isolate SIMCA classes are distinct and show no overlap. The strains assigned to region B included 17 strains originally assigned to cluster $18(S$. cyaneus), three to sub-cluster IA (S. albidoflavus), two to cluster 17 (S. griseoviridis), one to cluster 19 ( $S$. diastaticus), one to cluster 27 ( $S$. viridochromogenes), one to cluster 38 ( $S$. prasinosporus), two to cluster 61 ( $S$. lavendulae), one to cluster 71 ( $S$. clavuligerus) and one strain to a single member cluster ( $S$. amakusaensis). The acidophilic and the facultatively autotrophic strains along with two blue-spored soil isolates were also recovered in region $\mathbf{B}$.

\section{DISCUSSION}

The detection of major amounts of saturated iso- and anteiso-branched fatty acids of between 14 and 18 carbons in all the test strains was in good agreement with the results of previous studies on streptomycetes (Lechevalier, 1977; Kroppenstedt \& Kutzner, 1978; Kroppenstedt, 1985). It 
is difficult to evaluate the significance of fatty acid profiles in streptomycete systematics generally, since much of the early work was carried out on poorly described strains examined using a variety of experimental methods. Further, the overall similarities in streptomycete fatty acid profiles make it necessary to use numerical analyses to exploit the data for taxonomic purposes.

Despite the potential of quantitative analyses of fatty acid profiles in bacterial systematics most studies still rely on a qualitative interpretation of data where test strains are grouped according to whether they possess 'large amounts' or 'small amounts' of particular components. With the exception of a few numerically based studies (O'Donnell, 1985) this approach has generally resulted in fatty acid data being used to define taxa at generic and suprageneric levels. The development of simpler extraction and analysis systems together with the ability to obtain reproducible profiles (Saddler et al., 1986) provides a readily available but under-exploited source of taxonomic information.

The numerical approach adopted here involved two distinct processes. Initially, PCA was used to classify the test strains. The two-dimensional plot obtained gave a first approximation of the relationships between the strains, but the overall between-strain variation is rarely recovered exactly and inter-strain distances may be misrepresented (Sneath \& Sokal, 1973). The latter recommended that ordination methods be used in conjunction with numerically defined phenograms since these are more reliable for describing relationships between individual strains. The alternative approach adopted in the present study involved superimposing the results of a nearest neighbours analysis on the principal components plots.

It was particularly interesting that both the facultatively autotrophic and acidophilic strains were distinguished from the remaining test strains in the numerical analysis of fatty acid data. However, comparative studies on acidotolerant actinomycetes, that is, strains which grow at $\mathrm{pH} 4.5$ and $7 \cdot 2$, are needed to measure the effect of $\mathrm{pH}$ on fatty acid composition. The separation of the acidophilic from the neutrophilic actinomycetes and their recovery in more than one centre of variation was in good agreement with earlier findings (Williams et al., 1983; Lonsdale, 1985). Indeed, acidophilic actinomycetes are now known to be taxonomically very diverse (Lonsdale, 1985). The assignment of $S$. azureus ISP 5106 (strain 47), 'S. coralus' ISP 5256 (strain 30 ) and $S$. phaeoviridis ISP 5285 (strain 38 ) to the $S$. cyaneus class was also interesting as all three strains were classified in the $S$. cyaneus cluster in the $S_{J}$, UPGMA analysis (Williams et al., 1983); in the corresponding $S_{S M}$ analysis the latter two cultures were classified in the $S$. diastaticus cluster.

Two statistically significant principal component models were obtained when the fatty acid data were analysed by cross-validation (Wold, 1978). The latter operates by a process of removing and inserting elements from the data matrix and provides a useful method of separating the variable or object independent systematic variation from random noise. The concept of describing reproducibility in terms of systematic variation and random noise has no parallel in discriminant analysis (MacFie \& Gutteridge, 1982) and is discussed in detail by Blomquist et al. (1979a). This approach provided a means of evaluating the statistical stability and therefore the predictive potential of the groups recovered using PCA and KNN. This practice is of primary importance in any bacterial screening or identification system and in the evaluation of media formulations devised for the isolation of defined groups of bacteria (Williams et al., 1984; Goodfellow \& Williams, 1986). A problem arises, however, over whether a cluster or class deemed to be statistically significant is in fact valid microbiologically as judged by existing taxonomic criteria.

The test strains used to define the SIMCA class models were selected from $a$ priori information on the numerical phenetic and chemotaxonomic relationships of the strains. Consequently, strains which appeared to be closely associated with those used to define a given class model on the basis of their fatty acid data (Fig. 1) but which showed no relationship to them with respect to other criteria were not included. These strains were therefore treated as unknowns. Such an approach represents a working compromise since the question of strain selection for use in identification systems remains an as yet unresolved problem in microbial systematics and is in need of further investigation. 
The lack of congruence between classifications based on different analytical techniques can be expected to become increasingly common in bacterial systematics given the availability of an increasing number of techniques for generating taxonomic information on the same group of organisms (Sneath, 1985). When compared with the numerical phenetic classification (Williams et al., 1983) the results presented here support the inclusion of blue-, grey- and red-spored strains within $S$. cyaneus and the separation of this taxon from other numerically circumscribed streptomycete taxa. Further, the fact that not all of the strains received as $S$. cyaneus had quantitatively similar fatty acid profiles lends weight to the view that the numerically defined major streptomycete clusters may encompass strains that are not entirely typical of the cluster despite their high overall similarity with other members (Williams et al., 1983). The present data indicate that the $S$. cyaneus cluster is heterogeneous but further comparative studies using, for example, serological and nucleic acid pairing techniques need to be applied to determine the taxonomic status of the two statistically significant taxa obtained. Ridell et al. (1986) found that streptomycetes which shared a high number of precipitinogens belonged to the same numerically defined cluster, while strains less serologically related usually fell into different clusters. Similarly, Mordarski et al. (1986) obtained good congruence between numerical phenetic and DNA homology data with respect to strains assigned to the $S$. albidoflavus subcluster.

The increased use of analytical instrumentation in microbial systematics provides taxonomists with valuable new tools with which to study relationships between organisms. In many instances the data generated are multivariate and require the development and application of suitable data handling procedures. Since SIMCA pattern recognition techniques accommodate taxa with different within-group heterogeneities and uses them independently, they are likely to have an increasingly important role in microbial systematics. The data presented here demonstrate the potential of SIMCA pattern recognition in improving the interpretation of bacterial fatty acid data. As an identification or screening system the success of such a procedure depends on the construction and testing of statistically, as well as microbiologically, significant principal components models. The confidence limits set on these models can be tailored to suit particular problems although it is likely that the analysis of closely related taxa, in which there is a gradual shift from one species to another along a spectrum, will require the application of more stringent confidence intervals than the $95 \%$ interval used here. These problems will only be met by the application of such techniques to a large number of well defined taxa. It is possible that no one analytical or statistical technique will provide all the answers but the present data suggest that by analysing quantitative fatty acid data using SIMCA pattern recognition it should be possible to identify unknown actinomycetes to established taxa.

The authors are indebted to the Science and Engineering Research Council (grant GR/C/18830) for supporting part of this work and to Professor S. Wold for providing the SIMCA package. G. S. Saddler gratefully acknowledges receipt of an SERC/CASE award tenable at the University of Newcastle and ICI (Natural Products Group).

\section{REFERENCES}

Blomquist, G., Johansson, E., SöDerstrom, B. \& WOLD, S. $(1979 a)$. Data analysis of pyrolysis chromatograms by means of SIMCA pattern recognition. Journal of Analytical and Applied Pyrolysis 1, 53-65.

Blomquist, G., Johansson, E., SÖDerstrom, B. \& WOLD, S. (1979b). Reproducibility of pyrolysis-gas chromatographic analyses of the mould Penicillium brevi-compactum. Journal of Chromatography 173, 717.

Blomquist, G., Johansson, E., SöDerstrom, B. \& WoLd, S. (1979c). Classification of fungi by means of pyrolysis-gas chromatography pattern recognition. Journal of Chromatography 173, 19-32.
Embley, T. M., Goodfellow, M., Minnikin, D. E. \& O'DONNELL, A. G. (1984). Lipid and wall amino acid composition in the classification of Rothia dentocariosa. Zentralblatt für Bakteriologie, Mikrobiologie und Hygiene, series $A$ 257, 285-294.

FIX, E. \& HoDGES, J. L. (1951). Discriminatory analysis, non-parametric discrimination. USAF School of Aviation Medicine, Randolph Field, Texas, Project 21-49-004, Report 4.

Goodfellow, M. \& Williams, S. T. (1986). New strategies for the selective isolation of industrially important bacteria. Biotechnology and Genetic Engineering Reviews 4, 213-262.

GOWER, J. C. (1966). Some distance properties of 
latent root and vector methods used in multivariate analysis. Biometrika 53, 325-338.

HÜTTER, R. (1962). Zur Sytematik der Actinomyceten. 8. Quirlbildende Streptomyceten. Archiv für Mikrobiologie 43, 356-391.

KORN, F., WeingartNer, B. \& KUTZNer, H. J. (1978). A study of twenty actinophages: morphology, serology, relationship and host range. In Genetics of Actinomycetales, pp. 251-270. Edited by E. Freerksen, I. Tárnok \& J. H. Thumin. Stuttgart: Gustav Fischer Verlag.

KROPPENSTEDT, R. M. (1985). Fatty acid and menaquinone analysis of actinomycetes and related organisms. In Chemical Methods in Bacterial Systematics, pp. 173-199. Edited by M. Goodfellow \& D. E. Minnikin. London: Academic Press.

KROPPENSTEDT, R. M. \& KUTZNER, H. J. (1978). Biochemical taxonomy of some problem actinomycetes. Zentralblatt für Bakteriologie, Parasitenkunde, Infektionskrankheiten und Hygiene, Abteilung I, Supplement 6, 125-133.

LeCheVAlier, M. P. (1977). Lipids in bacterial taxonomy - a taxonomist's viewpoint. Critical Reviews in Microbiology 5, 109-210.

LeCheValieR, M. P. \& LechevalieR, H. A. (1970). Chemical composition as a criterion in the classification of aerobic actinomycetes. International Journal of Systematic Bacteriology 20, 435-443.

LONSDALE, J. T. (1985). Aspects of the biology of acidophilic actinomycetes. $\mathrm{PhD}$ thesis, The University of Newcastle upon Tyne, UK.

MacFie, H. J. H. \& GutTeridge, C. S. (1982). Comparative studies on some methods for handling quantitative data generated by analytical pyrolysis. Journal of Analytical and Applied Pyrolysis 4, 175204.

Minnikin, D. E. \& O'Donnell, A. G. (1984). Actinomycete envelope lipid and peptidoglycan composition. In The Biology of the Actinomycetes, pp. 337-388. Edited by M. Goodfellow, M. Mordarski \& S. T. Williams. London: Academic Press.

Minnikin, D. E., Hutchinson, I. G., Caldicott, A. B. \& Goodfellow, M. (1980). Thin-layer chromatography of methanolysates of mycolic acidcontaining bacteria. Journal of Chromatography 188, 221-233.

MordarsKa, H., Mordarski, M. \& Goodfellow, M. (1972). Chemotaxonomic characters and classification of some nocardioform bacteria. Journal of General Microbiology 71, 77-86.

MoRdarsKi, M., GoOdFellow, M., Williams, S. T. \& SNEATH, P. H. A. (1986). Evaluation of species groups in the genus Streptomyces. In Biological, Biochemical and Biomedical Aspects of Actinomycetes. Edited by G. Szabó, S. Biró \& M. Goodfellow. Budapest: Kiado Press.

O'DonNell, A. G. (1985). Numerical analysis of chemotaxonomic data. In Computer-assisted Bacterial Systematics, pp. 403-414. Edited by M. Goodfellow, D. Jones \& F. G. Priest. London: Academic Press.
O'Donnell, A. G., Goodfellow, M. \& Minnikin, D. E. (1982). Lipids in the classification of Nocardioides: reclassification of Arthrobacter simplex (Jensen) Lochhead in the genus Nocardioides (Prauser) emend. O'Donnell et al. as Nocardioides simplex comb. not. Archives of Microbiology 133, 323-329.

O'Donnell, A. G., Minnikin, D. E., Goodfellow, M. \& Piot, P. (1984). Fatty acid, polar lipid and wall amino acid composition of Gardnerella vaginalis. Archices of Microbiology 138, 68-71.

Pridham, T. G. \& Tresner, H. D. (1974). Streptomyces Waksman and Henrici 1943, 339. In Bergey's Manual of Determinative Bacteriology, 8th edn, pp. 748-829. Edited by R. E. Buchanan \& N. E. Gibbons. Baltimore: Williams \& Wilkins.

Ridell, M., WallerströM, G. \& WILliams, S. T. (1986). Immunodiffusion analyses of phenetically defined strains of Streptomyces, Streptoverticillium and Nocardiopsis. Systematic and Applied Microbiology 8, 24-27.

SADDler, G. S., Goodfellow, M., Minnikin, D. E. \& O'Donnell, A. G. (1986). Influence of the growth cycle on the fatty acid and menaquinone composition of Streptomyces cyaneus NCIB 9616. Journal of Applied Bacteriology 60, 51-56.

Skerman, V. B. D., McGowan, V. \& SNeath, P. H. A. (1980). Approved lists of bacterial names. International Journal of Systematic Bacteriology 30, 225420.

SNEATH, P. H. A. (1985). Future of numerical taxonomy. In Computer-assisted Bacterial Systematics, pp. 415-431. Edited by M. Goodfellow, D. Jones \& F. G. Priest. London: Academic Press.

SNEATH, P. H. A. \& Sokal, R. R. (1973). Numerical Taxonomy: The Principles and Practice of Numerical Classification. San Francisco: W. H. Freeman.

Wellington, E. M. H. \& Williams, S. T. (1978). Preservation of actinomycete inoculum in frozen glycerol. Microbios Letters 6, 151-157.

Williams, S. T., Goodfellow, M., Alderson, G., Wellington, E. M. H., SNeath, P. H. A. \& Sackin, M. J. (1983). Numerical classification of Streptomyces and related genera. Journal of General Microbiology 129, 1743-1813.

Williams, S. T., Goodfellow, M. \& Vickers, J. C. (1984). New microbes from old habitats? In The Microbe 1984, II, Prokaryotes and Eukaryotes, pp. 219-256. Edited by D. P. Kelly and N. G. Carr. Cambridge: University Press.

Wol.D, S. (1976). Pattern recognition by means of disjoint principal components models. Pattern Recognition 8, 127-139.

WoLD, S. (1978). Cross-validatory estimation of the number of components in factor and principal components models. Technometrics 20, 397-405.

Wold, S. \& SJøSTROM, M. J. (1977). SIMCA : a method for analysing chemical data in terms of similarity and analogy. In Chemometrics: Theory and Application, pp. 243-282. Edited by B. Kowalski. ACS Symposium Series no. 52, Washington, DC: American Chemical Society. 